\title{
A GESTÃO DEMOCRÁTICA NO MUNICÍPIO DE BRAGANÇA/PA E O TRABALHO DO CONSELHO MUNICIPAL DE EDUCAÇÃO NA EFETIVAÇÃO DA META 19
}

\author{
Ney Cristina Monteiro de Oliveiral \\ Kezya Helga de Souza Rodrigues da Silva²
}

\begin{abstract}
RESUMO
A Gestão democrática, enquanto princípio da educação nacional e meta específica a ser alcançada no Plano Nacional de Educação (2014) e nos Planos subnacionais de Educação, continua a ser um grande desafio para estados e municípios em suas respectivas redes de ensino. O trabalho dos órgãos colegiados de representação da sociedade civil, tais como os Conselhos de Educação são legalmente e socialmente fundamentais para seu fortalecimento e exercício na prática da política educacional. Este artigo busca então analisar a execução da meta 19 (Meta da Gestão Democrática) proposta no Plano Municipal de Educação de Bragança - PA, no período de 2015 a 2017 e o trabalho do Conselho Municipal de Educação para sua efetividade na realidade educacional daquele município. A abordagem metodológica adotada foi de natureza qualitativa, desenvolvida por meio dos procedimentos da revisão bibliográfica e pesquisa documental, utilizando a técnica de análise de conteúdo. A investigação apontou o frágil acompanhamento e monitoramento da execução das estratégias da meta da gestão democrática, a incipiente utilização do plano municipal como documento orientador das ações da política educacional, assim como explicita as dificuldades encontradas pelo Conselho Municipal de Educação, enquanto instância de gestão democrática municipal.
\end{abstract}

Palavras-chave: Planejamento Educacional. Gestão Democrática. Conselho Municipal.

\footnotetext{
1 Doutora em Educação (Currículo) pela Pontifícia Universidade Católica de São Paulo, Professora Titular da Universidade Federal do Pará, Docente do Programa de PósGraduação em Currículo e Gestão da Escola Básica (PPEB), Professora do Programa de Doutorado em Educaçao em Rede da Amazonia - PGEDA/EDUCANORTE, vinculado ao Núcleo de Estudos Transdisciplinares em Educação em Educação Básica NEB/UFPA; Coordenadora do Grupo de Pesquisa sobre Estado e Educação na Amazônia/GESTAMAZON. Brasil. Orcid iD: https://orcid.org/0000-0002-8091-5213. E-mail: neycmo@ufpa.br

2 Mestra em Educação Básica pelo Programa de Pós-Graduação em Currículo e Gestão da Escola Básica (PPEB) da Universidade Federal do Pará; Professora efetiva da rede pública municipal de Ananindeva e Santa Bárbara, pesquisadora integrante dos grupos de pesquisa GESTAMAZON E GERU da Universidade Federal do Pará. Brasil. Orcid iD: https://orcid.org/0000-0001-9669-9167. E-mail: kezya.helga@hotmail.com
} 


\title{
DEMOCRATIC MANAGEMENT IN THE MUNICIPALITY OF BRAGANÇA (PARÁ) AND THE WORK OF THE MUNICIPAL EDUCATION COUNCIL IN THE EFFECTIVENESS OF
}

\author{
THE GOAL 19
}

\begin{abstract}
Democratic management, as a principle of national education and specific goal to be achieved in the National Education Plan (2014) and in the subnational Education Plans, remains a major challenge for states and municipalities in their respective education networks. The work of collegiate bodies representing civil society, such as the Education Councils, is legally and socially fundamental for their strengthening and exercise in the practice of educational policy. This article then seeks to analyze the execution of goal 19 (Democratic Management Goal) proposed in the Municipal Education Plan of Bragança, in the state of Pará, from 2015 to 2017 and the work of the Municipal Education Council for its effectiveness in the educational reality of that municipality. The methodological approach adopted was of qualitative nature, developed through the procedures of bibliographical review and documentary research, using the content analysis technique. The investigation pointed out (a) the fragile follow-up and monitoring regarding the execution of the strategies of the democratic management goal, (b) the incipient use of the municipal plan as a guiding document for educational policy actions, as well as (c) making explicit the difficulties encountered by the Municipal Education Council, as an instance of municipal democratic management.
\end{abstract}

Keywords: Educational Planning. Democratic management. City Council.

\section{LA GESTIÓN DEMOCRÁTICA EN EL MUNICIPIO DE BRAGANÇA/PA Y EL TRABAJO DEL CONSEJO MUNICIPAL DE EDUCACIÓN EN LA EFECTUACIÓN DE LA META 19}

\section{RESUMEN}

La gestión democrática como principio de la educación nacional y meta específica a ser alcanzada en el Plano Nacional de Educación (2014) y en los Planos Subnacionales de Educación, continúa siendo un gran desafío para los estados y los municipios en sus respectivas redes de enseñanza. El trabajo de los órganos colegiados de representación de la sociedad civil, tales como los Consejos de Educación, son legalmente e socialmente fundamentales para el fortalecimiento y ejercicio en la practica de la política educativa. Este artículo busca analizar la ejecución de la meta 19 (Meta de la Gestión Democrática) propuesta en el Plano Municipal de Educación de Bragança - PA, en el periodo del 2015 al 2017 y los trabajos del Consejo Municipal de Educación para su efectividad en la realidad educativa de ese municipio. El abordaje metodológico adoptado fue de carácter cualitativo, desarrollado por medio de los procedimientos de revisión bibliográfica e investigación documental, utilizando la técnica de análisis de contenido. La investigación señaló el débil acompañamiento y monitoreo de la ejecución de las estrategias de la meta de la gestión democrática, el uso incipiente del plano municipal como documento orientador de las acciones políticas educativas, así como la explicita las dificultades encontradas por el Consejo Municipal de Educación, como instancia de Gestión Democrática Municipal.

Palabras clave: Planificación Educativa. Gestión Democrática. Consejo Municipal. 


\section{INTRODUÇÃO}

O presente trabalho, resultante de pesquisa de mestrado, objetiva analisar a execução da meta 19 - gestão democrática - no município de Bragança-PA e o trabalho do Conselho Municipal de Educação na efetivação das 15 estratégias da referida meta no período de 2015 a 2017.

A pesquisa, baseda na abordagem qualitativa, procurou trazer à tona as questões políticas, sociais e culturais, dos fenômenos ligados à democratização do planejamento e gestão da educação no município em que tela, indo muito além de questões ou dados quantificáveis do problema. Foi realizada a revisão bibliográfica a partir de autores que discutem a temática do planejamento e gestão da educação, resgatando conceitos, concepções e discussões a nível nacional, estadual e principalmente municipal no sentido de sustentar nossa análise. Quanto ao procedimento, trata-se de uma pesquisa documental, que utlizou para a análise documentos normativos (Leis, Portarias, Decretos e Resoluções) de âmbito nacional, estadual e municipal e os documentos orientadores, que são os que dão oficialidade à ação como Manuais e Cartilhas, voltados para executar os preceitos legais. Ademais foram ultizadas as atas e relatórios emitidos pelo Conselho Municipal de Educação de Bragança e o relatório de monitoramento do plano (2017a), enviado à Secretaria de Articulação com os Sistemas de Ensino (SASE/MEC) produzido pelo Fórum Municipal de Educação de Bragança; a técnica elencada foi a análise de conteúdo, baseada em Bardin (2016).

Assim, apresentamos aqui a análise realizada da meta da gestão democrática, que deriva nos planos subnacionais a partir do plano nacional (PNE/2014), seguida da investigação a respeito da execução da meta 19 no município de Bragança e o trabalho desenvolvido pelo Conselho Municipal de Educação de Bragança. 


\section{A META 19 DA GESTÃO DEMOCRÁTICA}

Após intensa disputa de quase quatro anos de tramitação no Congresso Nacional depois do término do Plano Nacional de Educação (2001-2010), foi aprovada em 25 de junho de 2014, sem vetos, a Lei 13.005/2014, que estabeleceu o novo PNE 2014-2024, possuindo 20 metas e 254 estratégias.

No que se refere à gestão democrática, garantida na Constituição Federal de 1988 como princípio constitucional e na Lei de Diretrizes e bases da Educação Nacional de 1996, também se apresenta no PNE com uma meta específica, que se desdobra em oito estratégias e estabelece a previsão de recursos e apoio técnico por parte da União, como podemos observar abaixo:

Meta 19: assegurar condições, no prazo de dois anos, para a efetivação da gestão democrática da educação, associada a critérios técnicos de mérito e desempenho e à consulta pública à comunidade escolar, no âmbito das escolas públicas, prevendo recursos e apoio técnico da União para tanto.(BRAGANÇA, 2015a).

O PNE 2014-2024 instituiu "metas ousadas e de grande importância, sobretudo à ampliação das oportunidades educacionais" (DOURADO, 2017, p. 72) e, ao contrário do PNE anterior, que não estipulou prazo, o novo PNE estabeleceu que Estados e Municípios elaborassem seus planos de educação ou adequassem os planos já existentes em consonância com o novo PNE, no prazo de um ano a partir da sua publicação.

Entre os muitos elementos os quais é possível analisar sobre as estratégias da meta da gestão democrática, destacamos as que fazem menção a atuação dos Conselhos de Educação que possuem como um de seus objetivos principais a participação na formulação dos planos estaduais e municipais de educação, a seguir com atenção para o município de Bragança, no estado do Pará.

Na política educacional, os Conselhos educacionais se tornaram importante instrumento de diálogo e tomada de decisão, ampliando os processos participativos na gestão e planejamento da educação. 
A partir da LDB de 1996, é estabelecido a partir de competência da União, no artigo $9^{\circ}$, inciso IX, parágrafo $1^{\circ}$, que "na estrutura educacional, haverá um Conselho Nacional de Educação, com funções normativas e de supervisão e atividade permanente, criado por Lei"; porém, não há menção a conselhos estaduais e municipais de educação, tampouco se institui a obrigatoriedade da criação destes, assim como também não o faz a CF de 1988. Para Bordignon (2009, p. 59), "essa omissão é coerente com o princípio constitucional da autonomia dos entes federados para organizar seus sistemas de ensino.

Os Conselhos de Educação assumiriam importante papel político na busca pela gestão democrática em todas as esferas administrativas, com o Conselho Nacional e os Conselhos Estaduais em todos as respectivas unidades, no Distrito Federal (DF) e em alguns municípios do país.

Embora os Conselhos, em qualquer esfera, devam assumir caráter de órgão de Estado, tanto passando a constituir-se espaço de cidadania e exercício de poder pelo povo quanto se associando aos ideais da sociedade, para Bordignon (2009), também podem assumir meramente caráter de governo, legitimando para a sociedade a vontade de determinado governo.

Os conselhos têm entre as suas muitas atribuições a de analisar, acompanhar, aprovar, assim como participar, na construção e execução dos planos de educação e na efetivação de suas metas. Eles têm entre as suas funções o caráter deliberativo, fiscalizador, legislativo, propositivo, consultivo, de mobilização e controle social, funções estas que ajudam no planejamento e na política educacional do município.

No município de Bragança ocorreu o movimento inverso, em que primeiramente foi elaborado e aprovado o plano no ano de 2015 e só posteriormente o Conselho passou a funcionar em 2016, depois de institucionalizada a Lei 4.476, aprovada em 18 de dezembro de 2015, que disciplina e organiza o sistema de ensino do município de Bragança. 
Segundo dados do IBGE (2019), existem atualmente conselhos de educação em todos os estados brasileiros; já em relação aos CMEs, os números são restritos e os motivos desta restrição, variados, visto que a política educacional fica muito vezes ao sabor dos governantes, que pouco (ou muito) compreendem sobre a importância e as potencialidades de tais órgãos. Trata-se assim de um eximir-se que reflete em uma perspectiva centralizadora que contraria as possibilidades de um cenário mais aberto e participativo.

A partir das atas fornecidas pelo CMEB referentes ao período de 2013 a 2018, encontramos informações sobre as reuniões de planejamento, a constituição da comissão eleitoral e a eleição dos conselheiros que comporiam a gestão 2016-2020, assim como sobre o trabalho desenvolvido quanto ao plano municipal de educação e a execução da referida meta, objeto de nosso estudo.

\section{A EXECUÇÃO DA META 19 DO PME E O TRABALHO DO CMEB}

Aprovado em 22 de junho a Lei $n^{\circ} 4.391 / 2015$, o Plano Municipal de Educação de Bragança, segundo consta em seu documento, teve sua elaboração precedida de reuniões, da realização da Conferência Municipal de Educação, em 3 e 4 de junho de 2013, do Fórum Municipal de Educação, ocorrido em 3 e 4 de junho de 2014, e de mais uma Conferência Municipal de Educação, em 28 e 29 de abril de 2015. Trata-se de informações importantes que, embora sem muito detalhamento, demonstram a intenção de fazer com que a proposta fosse construída com a participação dos variados segmentos da sociedade bragantina.

Quanto à meta 19, o PME de Bragança possui redação semelhante à do PNE 2014, sendo maior em número de estratégias, especificando suas necessidades. Porém assim como no PNE, o plano de Bragança não detalha em suas estratégias um período quantificável para o seu cumprimento, o que deixa margem para serem cumpridas em qualquer tempo dentro do período dos 10 anos. 
A seguir, consta o quadro 1, com a meta 19 e suas 15 estratégias com o status de "realizada", "em andamento" ou "não iniciada", como consta no relatório de monitoramento(2017a), estas estão agrupadas em 6 grupos a partir de nossa percepção, segundo aquelas que se assemelham no objetivo a ser perseguido pelo plano. O quadro demonstra a síntese das reais necessidades, identificadas naquele momento como necessárias para a efetivação da gestão democrática, que requer a participação e envolvimento dos segmentos sociais para garantia efetiva do cumprimento do ordenamento legal na área da educação municipal.

QUADRO 1 - Meta 19 do Plano Municipal de Educação de Bragança

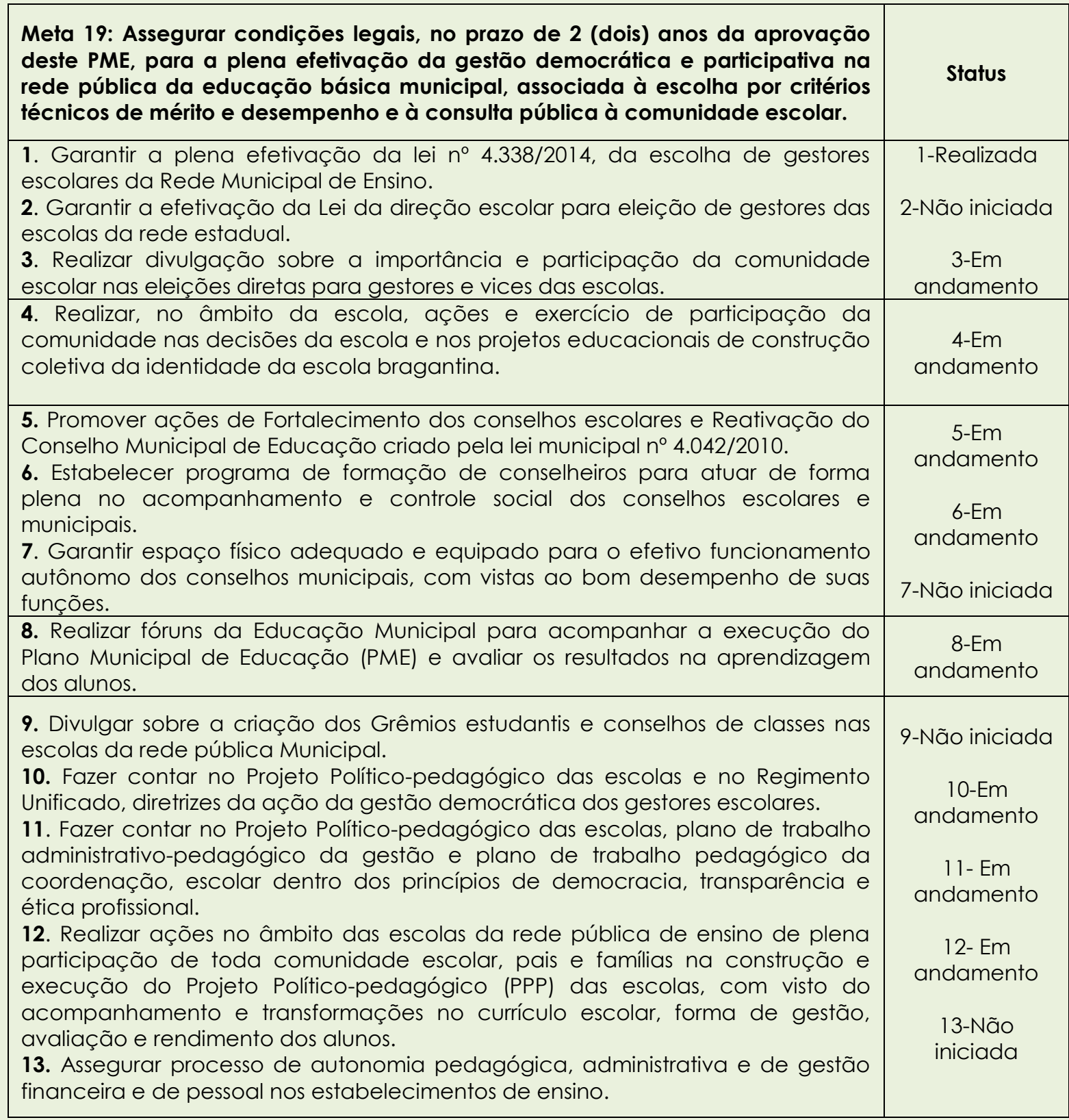


14. Desenvolver programas de formação continuada para diretores/gestores escolares dentro da concepção de educação de qualidade como direito social e garantia do aprender, bem como um programa de avaliação funcional de desempenho e excelência.

15. Garantir a participação dos profissionais da educação e da comunidade escolar, na revisão permanente da Proposta Pedagógica e do Regimento Escolar Unificado das instituições de ensino da rede municipal e estadual, com observância das Diretrizes Curriculares Nacionais e da proposta curricular do

14- Em andamento

15-Não iniciada município em todos os níveis e modalidades da educação municipal.

Fonte: elaborado a partir do Relatório de Monitoramento (Bragança 2017a).

Por meio do Relatório de Monitoramento (BRAGANÇA, 2017a), apresentado à SASE e referente ao biênio 2015-2017, encontramos Bragança como um dos 21 municípios paraenses a apresentar Relatório de Monitoramento do Plano com dados relativos à realização das estratégias propostas; constam nele suas 152 estratégias - naquele momento, com 37 realizadas, 93 em andamento e 22 não foram iniciadas. Dentre as 15 estratégias específicas da gestão democrática (meta 19), constavam 9 em andamento, 5 não iniciadas e apenas 1 realizada.

Na Lei do Plano Municipal de Educação, constam os responsáveis pelo seu monitoramento e avaliação de sua execução, no Artigo 5:

será de responsabilidade da Secretaria Municipal de Educação, em conjunto com o Fórum Municipal de Educação e o Conselho Municipal de Educação, avaliar a execução do Plano Municipal de Educação, estabelecendo os mecanismos necessários ao acompanhamento das metas (BRAGANÇA, 2015a).

Daquilo que depreendemos da análise das atas no período analisado, o conselho não centrou suas ações quanto ao processo de monitoramento do plano, debruçando seus esforços sobre outras ações, que naquele momento the pareceram ser mais emergenciais, como a regularização de escolas, por exemplo.

Devido aos poucos registros e estes dizerem respeito à realização da conferência e sobre o que a Semed estaria fazendo para monitorar o plano, entendemos que o conselho não atribuiu o processo de monitoramento à sua responsabilidade, considerando-o como tarefa da Secretaria Municipal de Educação. 
Este também não estabeleceu diálogo com o Fórum Municipal sobre esse processo, mesmo tendo uma representação na sua composição, o que demonstrou naquele momento uma desarticulação entre as três instâncias responsáveis pelo monitoramento do PME.

Ao analisarmos as atas do conselho, pudemos perceber quais movimentos foram empreendidos pelo órgão e como estes contribuíram ou não para a efetividade das estratégias propostas na meta 19 , referente à gestão democrática no período de 2016 e 2017.

A seguir, faremos a análise do status das estratégias mencionadas no relatório de monitoramento (2017a) fazendo relação com as informações mencionadas nas atas do conselho municipal de educação.

Sobre as estratégias com centralidade na eleição de gestores de escola - a existência da Lei de eleição direta de diretores e vice-diretores das escolas da rede municipal de ensino de Bragança é um dos principais elementos propostos no Plano Municipal e tem o objetivo de democratizar a gestão, que é destacado no diagnóstico do município juntamente com o fomento dos Conselhos escolares, de modo que ambos constam visados pelo poder público, antes da institucionalização do Conselho Municipal de Educação.

Em Bragança, a Lei municipal $n^{\circ} 4.338 / 2014$, dispõe sobre a escolha, mediante eleição direta de diretores e vice-diretores das escolas da rede municipal de ensino e dá outras providências, tornando-se a primeira estratégia proposta dentro da meta 19, segundo o monitoramento, com status de "realizada". Aprovada pela câmara e sancionada pelo prefeito em 14 de novembro de 2014, a Lei trata a respeito do processo de eleição, comissão eleitoral, eleitores e candidatos, propaganda e apuração de votos, definindo como se darão os processos sob autonomia das escolas da rede municipal e de seus respectivos conselhos escolares.

Quando O CMEB foi institucionalizado no município, uma das suas primeiras ações foi realizar uma diagnose nas escolas da zona urbana e do campo no município a fim de ter ciência das condições estruturais, 
administrativas e pedagógicas, embora nem todas pudessem ser visitadas devido à dificuldade/falta de transporte. Foram visitadas 45 escolas, 23 na zona urbana e 22 do campo, de um total de 131 na rede naquele ano (2016), sendo encontrados, por meio de eleição, diretores em 34 escolas (20 na zona urbana e 14 no campo).

Nas atas do Conselho, houve vários momentos no ano de 2017 em que as discussões foram em torno da Lei municipal da eleição de diretores e vicediretores nas escolas municipais em Bragança, o que designou um processo de propostas de modificações a serem realizadas na referida Lei.

No debate promovido pelo conselho municipal no que diz respeito à implementação das eleições diretas, percebe-se a divergência entre a percepção do conselho e a percepção da Secretaria Municipal de Educação quanto ao processo de eleição.

Na percepção da Secretaria Municipal de Educação, só haveria eleições em escolas que tivessem acima de 200 alunos, assim como os alunos das escolas anexas não entrariam nesta contagem das escolas polos, que naquele ano eram de 15 escolas polos e 84 anexas, segundo o Relatório de Monitoramento (BRAGANÇA, 2017a). Assim, haveria menos escolas com diretor eleito por voto direto e consequentemente mais escolas com pessoas nomeadas pelo secretário; ademais, com isso se evitaria a criação de duas novas funções (diretor e vice), o que para o executivo economizaria na folha de pagamento, como mencionado acima.

Diferentemente da Secretaria, consta nas atas que O CMEB se posicionou contra esta postura, entendendo que $O$ processo de participação nas eleições deveria ser garantido a todas as escolas, polos e anexas, bem como a todos os segmentos que as compõem. Assertivamente, ao compreender a importância da participação de todos no processo, o Conselho contribuiu para que a conservação deste direito criado por lei fosse garantido.

Sobre a estratégia 2, quanto à rede estadual, o processo de eleição para diretores vice-diretores é regido pela Lei estadual $n^{\circ} 7.855$ de 12 de 
maio de 2014, que possui estrutura semelhante em relação aos itens de orientação do processo e consta com status de "não iniciada". Em nossa análise, esse status se dá pela autonomia dos diferentes sistemas de ensino estadual e municipal - e pelo regime de colaboração ser um processo ainda em fase de desenvolvimento.

A respeito da divulgação sobre a importância da participação da comunidade escolar nas eleições diretas, o relatório apresenta o termo "em andamento", que nos faz inferir sobre uma ação ainda processo nas escolas da rede municipal de educação. Sobre isso, como anteriormente mencionado, o CMEB adiou para 2018 a audiência pública a respeito do assunto, sendo assim encontrados registros pontuais nas atas de 2017 sobre processos de divulgação e orientação sobre eleição direta nas escolas somente aos diretores, em algumas reuniões convocadas pela SEMED. Em nossa análise, as ações do CMEB em relação ao grupo 1 centralizaram-se nas funções fiscalizadora e normativa.

Quanto a Estratégia com centralidade no Fomento da participação intra-escolar - assim como as outras, esta quarta estratégia envolve a todos os munícipes e propõe o exercício da participação, processo este necessário também para a efetividade de outras estratégias do plano; além disso, por esta ser também subjetiva, necessita de constante busca, sendo encontrada com status de "em andamento" no Relatório de Monitoramento (2017a).

De certa maneira, a referida estratégia contempla-se nas outras estratégias da meta 19, devido ao fato de a participação ser um elemento necessário dentro e fora da escola, constituindo-se como item indispensável na gestão pública educacional para uma gestão democrática.

A discussão da participação defendida na estratégia 4 implica necessariamente a percepção da necessidade de uma perspectiva formativa para o exercício da democracia, assim como da descentralização das decisões, quando se tem maior chance de promoção da democratização ao se assumir uma postura política, conforme defendido por Novaes e Fialho (2010). 
Na análise de Lima (2011), a participação como um fenômeno sociológico "nunca é uma conquista definitiva" (p. 95), estando em constante busca como direito fundamental, tal como para a formação da cidadania.

Em relação às ações do conselho na contribuição para a efetividade da estratégia, existe um registro encontrado em 18 de maio de 2017, no qual há o desejo de se fazer um encontro de pais da rede municipal de ensino, em que:

\begin{abstract}
segundo a presidente aproveitando a fala de uma conselheira 0 CMEB tem três desafios: $1^{\circ}$ ) fazer esse encontro regional dos conselhos municipais, $2^{\circ}$ ) fazer o encontro com os pais e $3^{\circ}$ A Lei do Sistema que a cada leitura que fazemos percebe-se que necessita de alterações (BRAGANÇA, 2017b).
\end{abstract}

Promover a participação da comunidade nas decisões da escola também implica, segundo Gadotti (2008), estabelecer canais de participação, autonomia dos movimentos sociais e transparência administrativa; porém, de "nada adiantam todas as condições se a população for chamada apenas para legitimar as decisões tomadas em gabinetes" (GADOTTI, 2008, p. 48).

As ações do CMEB a favor da estratégia se deram de forma pontual, tendo como exemplo o encontro de pais realizado e as orientações a respeito da autorização de escolas com os que procuravam o conselho, de modo que ainda eram ações que estavam distantes do âmbito escolar.

Sobre as estratégias com centralidade nos Conselhos - terceiro grupo de estratégias, a estratégia 5 é composta de dois grandes desafios, o fortalecimento dos conselhos escolares e a reativação do conselho municipal, sendo este segundo institucionalizado no ano de 2016. No entanto, por ainda persistir o desafio do fortalecimento dos conselhos escolares, a estratégia encontra-se no Relatório de Monitoramento com status de "em andamento" (BRAGANÇA, 2017a).

A estratégia 6 está relacionada à formação dos conselheiros, visando à atuação nos conselhos escolares municipais, e também se encontra com status de "em andamento", segundo o Relatório de Monitoramento. 
Já a estratégia 7 possui status de "não iniciada" e afirma que o espaço físico e o equipamento adequados, necessários para o funcionamento dos conselhos municipais, ainda não foram conquistados por estes espaços colegiados no período analisado.

A respeito das ações do CMEB em relação aos Conselhos escolares, consta em documento elaborado com uma diagnose inicial, realizada em 2016, nas 45 escolas visitadas, que: de 23 escolas da zona urbana, todas possuíam Conselho escolar, sendo que " 18 estão ativos e 5 vencidos ou em processo de eleição para a nova diretoria" (BRAGANÇA, 2016a, p. 1).

Sobre a situação dos conselhos no campo, foi observado que havia conselho nas escolas polo, porém, "a maioria das escolas anexas no interior não possuem conselho escolar devido o número reduzido de alunos que variam entre 08 a 25 por turma" (BRAGANÇA, 2016a, p. 1). Estes números justificam-se, segundo o relatório, pela quantidade de turmas multisseriadas ou com sistema modular de ensino.

No Relatório de Monitoramento, para as referidas estratégias do grupo 3, constam previsões orçamentárias a cargo do FNDE/MEC, que podem ser encontradas, por exemplo, por meio do Programa Dinheiro Direto na Escola (PDDE), Programa Nacional de Capacitação de Conselheiros Municipais de Educação (Pró-Conselho) e o Programa Nacional de Fortalecimento dos Conselhos Escolares.

Contudo, a respeito do fortalecimento dos conselhos escolares e do estabelecimento de programas de formação dos conselheiros, não foram encontradas informações sobre ações efetivas por parte do CMEB direcionadas a estas estratégias, evidenciando que, pelo menos naquele momento, não estiveram no centro das pautas discutidas.

Os conselhos escolares como mecanismos de gestão democrática dentro das escolas são permeados por concepções diferentes e em disputa no que se refere à gestão educacional. A multiplicidade de suas competências pode, pelas circunstâncias e pela falta de formação ser direcionada a determinados objetivos e inobservância de outros, como por 
exemplo, quanto à supervalorização do aspecto financeiro, como apontado por Silva (2007).

os recursos adicionais destinados a unidades executoras representam para os conselhos escolares a substituição de suas prioridades pedagógicas e educativas, que são transformadas em atribuições de controle, acompanhamento contábil e prestações de contas dos gastos realizados pelas escolas. Assim, a lógica gerencial predomina em função do modelo de financiamento das escolas, que subordina as necessidades pedagógicas e educativas à supremacia dos aspectos administrativos (SILVA, 2007, p. 7).

Apesar de o CMEB não ter promovido ações mais efetivas quanto à formação dos conselheiros escolares, este colegiado por sua vez, no que diz respeito à estratégia 7 sobre espaço físico e equipado para o funcionamento autônomo dos conselhos, embora com status de 'não iniciada' foi motivo de pauta por diversas vezes nas plenárias do Conselho Municipal de Educação.

Após haver saído de um espaço provisório próximo à Câmara Legislativa Municipal, o CMEB não possuiu sede própria desde a posse dos conselheiros em 21 de junho 2016 até setembro de 2016, quando o Poder Executivo devolveu o imóvel ao proprietário, segundo informações da secretaria de educação.

A autonomia é um dos fundamentos necessários à gestão democrática, "as condições de funcionamento do conselho indicam o grau de autonomia e sua importância na gestão do sistema de ensino" (BORDIGNON, 2009, p. 80). A falta de espaço físico para o funcionamento autônomo do Conselho, em nossa análise, foi uma pauta perseguida por este colegiado por afetar diretamente o desempenho das funções dos conselheiros, portanto, significou uma pauta prioritária entre as muitas a serem reivindicadas.

Como órgão fiscalizador do estado, "depender da vontade do secretário para qualquer despesa implica em subordinação que, inevitavelmente, afeta o grau de autonomia de funcionamento do conselho" (BORDIGNON, 2009, p. 84); por isso, é de suma importância o conselho possuir dotação orçamentária própria. 
As condições materiais de um conselho são essenciais para o pleno exercício de suas competências. Segundo relatórios do conselho sobre o biênio 2016-2018, uma série de materiais permanentes e de expediente foram adquiridos pelo suporte dado pela Secretaria, o que já viabiliza grande parte dos trabalhos.

As ações do CMEB em favor deste grupo de estratégias centraram-se na manutenção dele próprio e de sua estrutura física, relegando os conselhos escolares à competência das escolas, já que este colegiado na ocasião, não dispunha de recursos. Após todo esforço empreendido pela casa dos conselhos e espaço próprio do funcionamento do CMEB, a pauta de luta continua, visto que até o término desta pesquisa, janeiro de 2020, o município ainda não possuía a casa dos conselhos e o CMEB não possuía prédio próprio funcionando ainda em um espaço alugado.

Sobre a estratégia $8 \mathrm{com}$ centralidade nos Fóruns de Educação - o status "em andamento" do relatório do monitoramento do Plano, justifica-se em parte pela própria legislação na lógica de monitoramento, que determina o acompanhamento do plano por meio do artigo $6^{\circ}$ da Lei 4.391/2015 que institui O PME, "O Fórum Municipal de Educação será convocado anualmente para o acompanhamento da execução das metas e ações previstas no anexo I desta lei, emitindo parecer sobre a situação encontrada". A este respeito, também consta no mesmo artigo no $\S 2^{\circ}$ "O Fórum Municipal de educação será convocado, no mínimo, a cada cinco anos a partir da aprovação desta Lei, com o objetivo de avaliar, rever e adequar as metas e ações contidas no anexo I, desta lei".

Segundo o Plano Municipal de Educação (BRAGANÇA, 2015a), antes de sua aprovação, houve um Fórum e uma Conferência Municipal de Educação, nos anos 2013 e 2014 respectivamente; consta no Relatório de Monitoramento (BRAGANÇA, 2017a) que estes dois momentos foram provocados pelo Fórum instituído pelo Decreto n. ${ }^{\circ} 187$ de 7 de maio de 2013, em que, o relatório também menciona que o produto dela foi fundamental para servir de base para a posterior construção do plano e das discussões 
que persistiriam por meio do Fórum ocorrido em 2014. Neste, foram divididos grupos de trabalho que discutiram e sistematizaram as ações, com base no manual de orientações da conferência nacional e estadual, produzido em 2013 pelo Fórum Nacional de Educação.

Os dois momentos e os debates em torno dos grupos culminaram, em 2015, na chamada IV Conferência Municipal, que serviria para a discussão e aprovação do plano com a comissão organizadora (membros do fórum): "a Equipe técnica sistematizadora e um grupo representativo das escolas municipais, estaduais, particulares, da Secretária de Promoção Social, da Saúde, dos Conselhos. E demais membros da sociedade civil representada" (BRAGANÇA, 2015a, p. 12-13).

Assim, dois meses após a Conferência, realizados os ajustes necessários ao texto e a aprovação deste na Câmara, o prefeito o sancionou em 22 de junho, dentro ainda do prazo final de um ano estabelecido pela lei do PNE. Naquele mesmo período e paralelamente, aconteciam as discussões em torno da Lei do Sistema, aprovada naquele mesmo ano em dezembro e também sendo instituído o Conselho Municipal de Educação.

Com a posse do conselho, seus membros assumiram diversas demandas, entre elas, participar da avaliação do plano como estabelecido em lei, fato este que ocorreu em 2017, por meio de uma representação dentro do Fórum. No entanto, o Fórum, o Conselho e a Secretaria Municipal de Educação, responsáveis em conjunto pela avaliação do plano, pareceram estar fragmentados em seus objetivos, assim como em desacordo quanto ao compartilhamento de informações a respeito do monitoramento.

Outra situação inferida é a de que o Fórum acabou se tornando coadjuvante, subjugado à Semed, quando deveria ter igual importância, ou melhor, estar exercendo o papel de protagonista do processo juntamente com o Conselho, visto que estes representam segmentos importantes da sociedade civil. 
Quanto as estratégias com centralidade na autonomia e planejamento da gestão da escola - quinto agrupamento de estratégias, a estratégia 9 diz respeito aos grêmios e conselhos de classe, duas instâncias colegiadas importantíssimas que visam a promover o diálogo entre os diferentes segmentos que compõem a escola.

O grêmio estudantil possui base legal na Lei federal $n^{\circ} 7.398$ de 4 de novembro de 1985, que "dispõe sobre a organização de entidades representativas dos estudantes de $1^{\circ}$ e $2^{\circ}$ graus e dá outras providências" (BRASIL, 1985). O grêmio representa os interesses dos alunos e possibilita dar voz oficial às demandas estudantis dentro da gestão escolar, assim assegura que tenham suas "finalidades educacionais, culturais, cívicas esportivas e sociais" (BRASIL, 1985, art. 1\%).

Já quanto ao conselho de classe, este consiste em uma instância colegiada promovida por meio de reuniões, na maioria das vezes, podendo ser composto de diferentes formas pelos segmentos de profissionais da escola, pais/responsáveis e alunos, visando à avaliação da aprendizagem.

A estratégia 9 sobre grêmios e conselhos de classe, que inicia meramente com o verbo "divulgar", já demonstra uma ação sem garantia e meramente informativa, utilizada por muitos legisladores para desviar sua obrigatoriedade. O termo acaba colaborando para a criação de uma estratégia frágil, embora não exclua a possibilidade de sua concretude no âmbito escolar. Entre as ações concretas por parte do CMEB, não foram encontrados a esse respeito registros nas atas e relatórios do período analisado.

Quanto às estratégias 10, 11 e 12, caracterizadas pelo relatório como "em andamento", estas assemelham-se por terem importantes documentos como instrumentos de democratização da gestão escolar, sendo estes o Projeto Político Pedagógico (PPP), O Regimento Unificado, O Plano administrativo-pedagógico da gestão e o plano de trabalho pedagógico da coordenação escolar, assim como as ações que visavam à execução destes sob acompanhamento da comunidade escolar. 
A respeito desses documentos, a partir dos relatórios de visitas às escolas foram constatados "que a maioria das escolas independentes e polo estão com o PPP vencido ou em construção e há situações, onde este documento ainda não existe" (BRAGANÇA, 2016b, p. 2). Ainda sobre os PPPs nas escolas da zona urbana, entre as 23 escolas visitadas, "constatamos que 21 possuem PPP ou suas propostas pedagógicas, em 6 escolas estes estão vigentes e em 15 escolas estão vencidos ou passando por avaliação e em 2 escolas ainda não possuem esse documento" (BRAGANÇA, 2016b, p. 1).

O Projeto Político Pedagógico colocado como um dos vários itens a serem analisados pelo CMEB para a autorização e renovação de autorização de escolas, de forma periódica, faz com que a função normativa do conselho alia-se à função fiscalizadora com a exigência de construir a proposta pedagógica da escola, pelo menos em tese.

Quanto ao regimento, O CMEB estabelece em sua resolução $n^{\circ}$ 01/2017 que, assim como o PPP, as escolas terão a incumbência de elaborar e executar seus regimentos escolares; porém, em relatório do CMEB até junho de 2018, apenas 2 estabelecimentos deram entrada com processo de aprovação de seu regimento escolar, sendo elas da rede privada.

Sobre os planos de trabalho da gestão e coordenação de escola, que constam na estratégia 11 , estes não encontram-se exigidos nas resoluções do CMEB no período analisado, em que constam como incumbências: dos estabelecimentos de ensino, como a de "IV. Velar pelo cumprimento do plano de trabalho de cada docente" (BRAGANÇA, 2017c, art. $3^{\circ}$, inciso IV); e dos professores, como a de "ll. Elaborar e cumprir plano de trabalho, segundo a proposta pedagógica do estabelecimento de ensino" (BRAGANÇA, 2017c, art. 4 , inciso II).

Exigir dos professores planos de trabalho em consonância com a proposta pedagógica do estabelecimento de ensino, sem esta possuir uma além de algo contraditório, demonstra tanto a fragilidade do planejamento educacional escolar quanto a desarticulação com a proposta desenvolvida pelo município, referente a metas e objetivos. 
Sobre a estratégia 11, quanto aos planos de trabalho da gestão escolar, consta na Lei 4.338/2014, que se refere à eleição de diretores e vicediretores, percebemos o quanto estão articulados pela legislação o plano da gestão, a participação da comunidade e o projeto político pedagógico, ou seja, a fragmentação ou não concretude/fomento de qualquer um destes deslegitima a ação dos outros, razão pela qual estão intrinsecamente ligados e interdependentes. Contudo, durante o período analisado, não foram encontrados registros a respeito de ações mobilizadoras ou propositivas por parte do conselho, no sentido de viabilizar ou corroborar com a construção destes documentos juntamente às escolas, o que interfere diretamente na execução da estratégia 12.

A respeito da estratégia 13, com status de "não iniciada", encontra-se amparada pela Lei $n^{\circ} 9.394 / 96$ que estabelece "Art. 15. Os sistemas de ensino assegurarão às unidades escolares públicas de educação básica que os integram progressivos graus de autonomia pedagógica e administrativa e de gestão financeira, observadas as normas gerais de direito financeiro público" (BRASIL, 1996).

Considerada pelo Relatório de Monitoramento (2017a) como não iniciada, revela que esta e as demais estratégias do grupo 5, tiveram ações do CMEB centralizadas nas funções normativa, fiscalizadora, deliberativa e consultiva, contemplando aspectos técnicos de operacionalização e organização da escola, estas prejudicadas pelo distanciamento de suas funções propositivas e mobilizadoras, algo que fortaleceu o engessamento do processo burocrático administrativo de suas ações.

Sobre as estratégias com centralidade na formação continuada quanto à estratégia 14, sobre programas de formação para diretores/gestores escolares, com status "em andamento", foram encontradas nas atas fornecidas pelo conselho mais momentos descritos como "reuniões" do que momentos chamados de "formações", os quais foram realizados pela SEMED durante o período analisado. 
Embora a lei municipal $n^{\circ} 4.338 / 2014$, que dispõe sobre a eleição de diretores e vice-diretores, especifique a formação dos candidatos à função, esta informação é alterada pela lei 4.374/2015 (BRAGANÇA, 2015d), no artigo 12 e inciso II, para que "tenha formação em curso de licenciatura plena em pedagogia ou outra licenciatura com especialização com especialização em gestão escolar"; ainda assim, o exercício da gestão requer dos gestores uma constante formação.

Ao promover orientações dentro das reuniões da SEMED, os conselheiros tornaram-se mais próximos dos gestores, esclarecendo dúvidas quanto a autorizações e renovações de autorização, mas também diretamente atuando em prol de seu estabelecimento político enquanto órgão do sistema municipal de ensino.

A respeito da última estratégia da meta, com status de "não iniciada", que consiste na garantia de participação na revisão do PPP e do Regimento, esta mais uma vez demonstra a necessidade da formação para os profissionais da educação e membros da comunidade escolar, ficando sem realização a contento durante o período analisado.

O Conselho quando recém-instituído ainda era permeado de algumas dúvidas quanto a aspectos legais que foram sendo resolvidas com o tempo, visto que não foi disponibilizado um assessor jurídico ao conselho, que tinha de recorrer ao Conselho Estadual de Educação e também ao assessoramento jurídico da União Nacional dos Conselhos Municipais de Educação (UNCME).

No que concerne à execução da meta 19 e suas 15 estratégias durante o período analisado, percebeu-se a centralidade das ações deste colegiado sobre suas funções normativas e fiscalizadoras, as quais estiveram engessadas pelas próprias condições encontradas nas escolas, com alta rotatividade de servidores, desmobilização social pela falta de participação, propostas pedagógicas defasadas ou inexistentes e condições precárias quanto à estrutura física. 
Embora não fornecesse maiores subsídios às escolas, o CMEB cumpriu com as incumbências do plano legal quanto às normativas de organização do sistema municipal de ensino e das escolas. Porém, estas não foram suficientes, dadas as condições existentes naquele momento, como a de promover processos formativos ou a de atuar junto às escolas em relações mais estreitas, podendo tornar-se referência aos conselhos escolares.

\section{CONSIDERAÇÕES FINAIS}

Esta pesquisa explicitou como se desenvolveu o processo de execução da meta 19 da gestão democrática do Plano Municipal de Educação de Bragança (2015-2025), além de cada uma de suas 15 estratégias durante o período de 2015 a 2017, analisando as ações do Conselho Municipal de Educação por meio da pesquisa qualitativa e do tipo documental.

A elaboração dos planos nacionais e subnacionais preconizava a participação de todos em sua elaboração, de modo que os movimentos sociais, Fóruns, Conferências e Conselhos tiveram fundamental importância na mobilização social.

A organização das normativas implementadas no município não seguiu uma dada ordem lógica comum, pois o Plano Municipal de Educação foi elaborado de forma a atender a exigência legal, preparando - caminho para a aprovação da Lei do Sistema, que, por sua vez, institucionalizou o Conselho Municipal de Educação.

O documento do Plano Municipal de Educação, no que tange à gestão democrática, dispensou focalizar dois principais fatores - a eleição de diretores de escola e a criação de conselhos escolares - constantes na diagnose no plano do município.

Assim, percebemos a centralidade em questões ligadas à participação intraescolar, em detrimento de ações em prol da democratização do sistema de ensino e sua articulação entre todos os órgãos que o compõem, de certa forma tornando-os elementos distintos e apartados dentro de um mesmo sistema. 
Quanto à análise a respeito do desempenho do conselho sobre as estratégias da meta 19, encontramos muitos desafios a serem enfrentados por este junto à gestão municipal e poucas possibilidades, no período analisado, de serem alcançadas. Esse fato refletiu-se no documento elaborado pelo Fórum Municipal de Educação sobre o monitoramento do plano.

Entre os principais desafios, destacamos a tímida articulação com os estabelecimentos de ensino e a falta de uma maior proximidade com as diferentes comunidades escolares para o fomento da participação e do controle social, como por exemplo, por meio de processos formativos.

Quanto ao PME, com maioria de estratégias em status de "em andamento" e tímida prospecção a respeito de ações mais amplas, o Conselho agiu de forma pontual, atendendo às necessidades da Secretaria Municipal de Educação e com poucas possibilidades estruturais de maiores ações, devido à falta de condições materiais e apoio institucional.

A importância de um conselho municipal de educação é inegável, já que sua importância junto ao planejamento e gestão da educação municipal possibilita uma maior abertura ao processo de democratização da educação, não só por meio da representação social mas do estímulo e formação da cidadania da sociedade e do fortalecimento e incentivo à criação de instâncias colegiadas.

A análise também evidenciou que o Plano Municipal de Educação, no período analisado, não foi objeto norteador das ações do CMEB, tal como não foi norteador da política educacional do município, demonstrando a falta de centralidade de ações em prol das estratégias, relegadas ao domínio da Secretaria Municipal, tal como sua avaliação e monitoramento, o que reforça o caráter pontual das ações e falta de articulação entre os órgãos do sistema.

Os planos de educação e a existência dos conselhos são importantes bandeiras de luta, travadas nos núcleos dos movimentos sociais, que levaram anos para ser traçadas. Em Bragança, a criação destes elementos, 
embora não totalmente articulada, iniciou processos de promoção da gestão democrática, considerada nas legislações do município centradas na eleição direta para diretores e vice-diretores e na criação de conselhos escolares, ambas as propostas voltadas à escola e não à democratização do sistema de ensino como um todo.

A necessidade de constante fortalecimento dos conselhos $e$ conselheiros de educação torna-se imprescindível perante um cenário de profundas mudanças políticas e ameaças às instâncias de participação democrática no país. O trabalho desenvolvido por estes com a sociedade na busca pela maior criticidade e envolvimento político na tomada das decisões, principalmente quanto ao planejamento, torna maiores as possibilidades da socialização do poder, embora o modelo neoliberal o restrinja ao modelo econômico, apropriando-se do termo e mudando seu sentido para o âmbito privado.

É necessário intensificar ações contra o ataque feroz à democracia e à democratização da educação nacionalmente, refletir sobre o quão importante é a existência de instâncias democráticas como os conselhos, assim como nos cabe o dever de defendê-los contra o desmonte da administração pública em seus diferentes níveis e a desvalorização do seu sentido além da a apropriação privada de seus colegiados. Com atenção, sobretudo, ao desmonte de órgãos de assessoramento aos estados e municípios na efetivação e monitoramento de seus planos de educação, como aconteceu com a SASE em 2019, e ao total desestímulo nacional à proposta de planos decenais de educação, processos que deixam ainda mais difícil a tão requerida efetivação dos planos e a concretização do sistema nacional de ensino.

Ainda há muito trabalho a ser empreendido pelo Executivo e pelos órgãos e instituições de representação da sociedade civil do município de Bragança, sobretudo, no sentido de ações mais efetivas quanto à proposição e mobilização da sociedade, assim como na vinculação e envolvimento destas à execução do planejamento 
proposto para o decênio 2015-2025, tendo relação direta com a execução da meta da gestão democrática, que, durante o período pesquisado, apresentou maiores dificuldades do que possibilidades de alcance até o fim de 2025.

\section{REFERÊNCIAS}

BARDIN, L. Análise de Conteúdo. São Paulo: Edições 70, 2016.

BORDIGNON, G. Gestão da Educação no Município: Sistema, Conselho e Plano. São Paulo: Instituto Paulo Freire, 2009.

BRAGANÇA (Pará). Lei n 4.042, de 29 de março de 2010. Cria o Conselho Municipal de Educação de Bragança e dá outras providências. Bragança: Câmara Municipal, [2010].

BRAGANÇA (Pará). Decreto n. 187, de 7 de maio de 2013. Institui o Fórum Municipal de Educação de Bragança. Bragança: Câmara Municipal, [2013].

BRAGANÇA (Pará). Lei $\mathbf{n}^{\circ} \mathbf{4 . 3 3 8}$, de 14 de novembro de 2014. Dispõe sobre a escolha, mediante eleição direta de diretores e vice-diretores das escolas da rede municipal de ensino de Bragança e dá outras providências. Bragança: Câmara Municipal, [2014].

BRAGANÇA (Pará). Lei n 4.391, de 22 de junho de 2015. Institui o Plano Municipal de Educação, em conformidade com a Lei Orgânica do Município de Bragança, com a Constituição do Estado do Pará, com a Constituição da República Federativa do Brasil e com a Convenção Americana de Direitos Humanos (Pacto San José da Costa Rica). Bragança: Câmara Municipal, [2015a]. Disponível em: <tinyurl.com/vxwhopd>. Acesso em: 11 jul. 2020.

BRAGANÇA (Pará). Lei $\mathbf{n}^{\circ}$ 4.476, de 18 de dezembro de 2015. Disciplina a organização do sistema de ensino do município de Bragança, estado do Pará, e dá outras providências. Bragança: Câmara Municipal, [2015b]. Disponível em: <tinyurl.com/wohycxo>. Acesso em: 11 jul. 2020.

BRAGANÇA (Pará). Secretaria Municipal de Educação. Ata de reuniōes plenárias do Conselho Municipal de Educação: 23 set. 2015. Bragança: Semed, 2015c.

BRAGANÇA (Pará). Lei 4.374, de 2015. Dá nova redação a lei 4.338/2014 quanto a formação dos candidatos a diretores e vice-diretores. Bragança: Câmara Municipal, [2015d].

BRAGANÇA (Pará). Relatório diagnóstico 1 das escolas municipais: cidade. Bragança: CMEB, $2016 a$.

BRAGANÇA (Pará). Relatório diagnóstico 2 das escolas municipais: campo. Bragança: CMEB, $2016 \mathrm{~b}$.

BRAGANÇA (Pará). Secretaria Municipal de Educação. Ata de reuniōes plenárias do Conselho Municipal de Educação: 7 dez. 2016. Bragança: Semed, 2016c.

BRAGANÇA (Pará). Secretaria Municipal de Educação. Ata de reuniões plenárias do Conselho Municipal de Educação: 26 out. 2016. Bragança: Semed, 2016 d. 
BRAGANÇA (Pará). Relatório de monitoramento do Plano Municipal de Educação. Bragança: Semed, 2017a.

BRAGANÇA (Pará). Secretaria Municipal de Educação. Ata de reuniōes plenárias do Conselho Municipal de Educação: 15 maio 2017. Bragança: Semed, 2017b.

BRAGANÇA (Pará). Resolução nº01 de janeiro de 2017. Dispõe sobre a regulamentação e a consolidação das normas municipais, estaduais e nacionais aplicáveis à Educação Básica no Sistema Municipal de Ensino de Bragança/ Pará. Bragança: CMEB, 2017c.

INSTITUTO BRASILEIRO DE GEOGRAFIA E ESTATÍSTICA (IBGE). Pesquisa de Informações Básicas Municipais - MUNIC. IBGE, [2019]. Disponível em: <tinyurl.com/v34U3hm>. Acesso em: 20 dez. 2019.

BRASIL. Lei $n^{\circ}$ 13.005, de 25 de junho de 2014. Aprova o Plano Nacional de Educação - PNE e dá outras providências. Brasília: Presidência da República, [2014a]. Disponível em: <tinyurl.com/z5m2dls>. Acesso em: 20 maio 2020.

BRASIL. [Constituição (1988)]. Constituição da República Federativa do Brasil. Brasília, DF: Presidência da República, [1988]. Disponível em: <tinyurl.com/sp2ttn6>. Acesso em: 10 jul. 2020.

BRASIL. Lei $\mathbf{n}^{0} \mathbf{7 . 3 9 8}$, de 4 de novembro de 1985. Dispõe sobre a organização de entidades representativas dos estudantes de $1^{\circ}$ e $2^{\circ}$ graus e dá outras providências. Brasília: Presidência da República, [1985]. Disponível em: <tinyurl.com/r6bpy62>. Acesso em: 20 dez. 2020.

BRASIL. Lei n. 9.394, de 20 de dezembro de 1996. Estabelece as diretrizes e bases da educação nacional. Brasília, DF: Presidência da República, [1996]. Disponível em: <tinyirl.com/y26cabgo>. Acesso em: 25 jan. 2020.

DOURADO, L. F. Plano Nacional de Educação: o epicentro das políticas de Estado para a educação brasileira. Goiânia: Ed. Imprensa Universitária; ANPAE, 2017. GADOTTI, M. Escola Cidadã. 12. ed. São Paulo: Cortez, 2008.

LIMA, L. C. A escola como organização educativa: uma abordagem sociológica. 4 ed. São Paulo: Cortez, 2011.

NOVAES, I. L.; FIALHO, N. H. Descentralização educacional: características e perspectivas. RBPAE, Porto Alegre, v. 26, n. 3, p. 585-602, set./dez. 2010.

PARÁ, Lei estadual $\mathbf{n}^{\circ} \mathbf{7 . 8 5 5}$ de 12 de maio de 2014. Institui e disciplina o processo de eleição direta para Diretor e Vice-Diretor de unidade escolar da rede estadual de ensino. Pará: assembleia legislativa, 2014.

SILVA, L. G. A. Plano Nacional de Educação: uma avaliação das diferentes concepções de gestão educacional em disputa. Linhas Críticas, Brasília, v. 13, n. 25, p. 253- 270, jul./dez. 2007.

Recebido em: 11 de setembro de 2020 . Aprovado em: 07 de março de 2021.

Publicado em: 26 de abril de 2021.

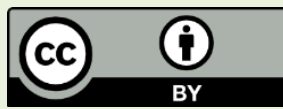

